\title{
Congenital sodium diarrhea
}

INSERM

\section{Source}

INSERM. (1999). Orphanet: an online rare disease and orphan drug data base. Congenital sodium diarrhea. ORPHA:103908

Congenital sodium diarrhea is characterized by severe watery diarrhea containing high concentrations of sodium, hyponatremia and metabolic acidosis. 